PUBLIC PERCEPTIONS OF ENERGY CHOICES: THE INFLUENCE OF BELIEFS ABOUT CLIMATE CHANGE AND THE ENVIRONMENT

$$
\text { by }
$$

Alexa Spence, Wouter Poortinga, Nick Pidgeon and Irene Lorenzoni

\author{
Reprinted from \\ ENERGY \& \\ ENVIRONMENT
}

VOLUME 21 No. 52010 


\title{
PUBLIC PERCEPTIONS OF ENERGY CHOICES: THE INFLUENCE OF BELIEFS ABOUT CLIMATE CHANGE AND THE ENVIRONMENT
}

\author{
Alexa Spence $^{\mathrm{a}^{*}}$, Wouter Poortingab ${ }^{\mathrm{b}}$ Nick Pidgeon $^{\mathrm{a}}$, and Irene Lorenzoni ${ }^{\mathrm{c}}$ \\ ${ }^{a}$ School of Psychology, Cardiff University, Tower Building, Park Place, Cardiff, CF10 3AT, UK. \\ ${ }^{b}$ Welsh School of Architecture, Cardiff University, Bute Building, King Edward VII Avenue, \\ Cardiff, CF10 3NB, UK. \\ ${ }^{c}$ School of Environmental Sciences and Tyndall Centre for Climate Change Research, \\ University of East Anglia, Norwich, NR4 7TJ, UK. \\ * Corresponding Author. Tel: +44 2920 876520; Fax: +44 2920874858. \\ Email address: SpenceAl@cardiff.ac.uk
}

\begin{abstract}
Past research has documented high levels of public concern for risks relating to nuclear power, with opposition to nuclear energy particularly being linked with general environmental concern. However recent UK energy policy, and other debates worldwide, has led to a repositioning of nuclear power as a 'low carbon' electricity source with potential benefits for mitigating climate change. Whilst many previous studies have examined perceptions of climate change and nuclear energy separately, this large British public attitude survey explores relationships between the two as well as with perceptions of other energy sources. Both general environmental concern and concerns about climate change were linked with positive evaluations of renewables and negative evaluations of nuclear power. We conclude that, despite the policy positioning of nuclear power as a low carbon electricity source, most people concerned about climate change continue to perceive nuclear negatively, something partially explained by general environmental concerns.
\end{abstract}

Keywords: Perceptions; Climate Change; Nuclear Power

\section{INTRODUCTION}

Climate change is receiving increasing attention in Britain and across the globe. The impacts of climate change are likely to be extensive and potentially devastating, supporting calls for urgent mitigation ${ }^{1}$. Reflecting this, the British government has set ambitious domestic emission targets, and as a result of the Climate Change Act 2008, the UK is legally bound to reducing its greenhouse gas emissions by at least $80 \%$ by 2050 (compared to 1990 levels). Achieving this target will require a consistent review of carbon-emitting sectors, including electricity generation and use. Electricity 
generated traditionally from fossil fuels (coal and gas) produces very high carbon emissions, whilst renewable energy sources (hydropower, wind, solar) are presently low carbon alternatives. In the UK context, however, reservations have been expressed regarding the short-term capacity of existing renewable technologies. In most cases these are not fully developed or commercially viable, and therefore are regarded as unable to realistically replace traditional modes of energy generation to satisfy current - let alone future increased - demand ${ }^{2}$. In this context, nuclear power has been presented by government and other groups as a low carbon option ${ }^{\mathrm{i}}$, and as such capable of providing an important part of Britain's future electricity generating capacity whilst emitting lower quantities of greenhouse gases than traditional fossil fuels ${ }^{2,3,4}$. Similar debates focusing on nuclear power as one part of the response to climate change are ongoing in other countries including the U.S. ${ }^{5,6}$ and across Europe, in particular within Germany ${ }^{7}$.

Although recently nuclear power has been framed as a low carbon energy source in comparison to other widely used technologies, this must be set against historic public concerns and anti-nuclear sentiment ${ }^{8}$. Whilst there is an abundance of surveys and polls examining public perceptions of climate change and energy sources separately, this paper presents a novel empirical examination of the relationships between evaluations of different energy sources and perceptions of both climate change and general environmental concern. Initial evidence has indicated that, when presented within the context of climate change, attitudes towards nuclear may become more positive $^{9,10}$. The relationship between these issues is closely examined in this paper, drawing upon data from a comprehensive nationwide survey of British public attitudes towards future energy options for the $\mathrm{UK}^{11}$.

\section{Attitudes towards climate change}

The public generally view the issue of climate change in a negative light ${ }^{12}$. Survey evidence from 2007 indicates that a large majority of people in Europe, including approximately $90 \%$ of the British public, expressed concern about climate change ${ }^{13}$. However, in the context of other concerns in people's lives, climate change tends to

\footnotetext{
${ }^{i}$ Estimating the extent of carbon dioxide 'saved' if current nuclear power generation is continued or augmented in the future is complex and subject to considerable debate. It depends not only upon the extent of emissions during operation but other lifecycle emissions (accrued during construction, fuel mining and fabrication) of both nuclear energy and alternatives, but also assumptions made about future generation/use scenarios were nuclear stations to be replaced with alternatives. Particular uncertainties also relate to the carbon emissions associated with site decommissioning and waste disposal. The UK 2006 Energy Review, for illustrative purposes, estimates that if existing nuclear power stations were replaced by new ones they would 'save' some 8 million tonnes of carbon (mtc) by 2030 in total, equivalent to the emissions from twenty-two 500MW gas-fired power stations (DTI, 2006, p. 17). When compared to replacement by conventional coal-fired stations, however, the 'saving' would be far larger (of the order of $16 \mathrm{mtc}$ ). However, compared to replacement by increased energy efficiency and changes in behaviour, or by low carbon renewable sources such as tidal and wind power, the carbon savings of nuclear power are negligible. As with so many aspects of the present energy debate, how the issue is framed is critical to the conclusions that can be drawn. Despite all of these uncertainties, the UK Sustainable Development Commission (2006) concluded that nuclear power is a low carbon source of electricity, albeit one which can only ever eliminate a relatively small percentage of the UK's total emissions (SDC, 2006).
} 
assume a lesser significance ${ }^{14,15,16}$. Although generally the public perceive the risks of climate change to outweigh the benefits ${ }^{12}$, people distinguish between personal and societal impacts of climate change with studies suggesting that societal risks are perceived to be higher than personal risks ${ }^{17,18,19}$ and perceive both risks and benefits at different spatial and temporal scales ${ }^{20}$.

A survey conducted in 2004 indicated that $52 \%$ of British respondents stated climate change would have little or no effect on them ${ }^{21}$. There is also some evidence that people perceive potential personal benefits relating to climate change, such as better weather ${ }^{22}$. However, individuals do acknowledge that more vulnerable groups and societies might bear the brunt of the negative impacts of climate change. Research indicates therefore that although people believe climate change to be mostly irrelevant for them personally, they are concerned about climate change ${ }^{20}$.

Individuals generally indicate willingness to take action on climate change and although a significant proportion assert they have already made changes to their lifestyles $^{23}$, many have not changed anything ${ }^{24}$. In addition, a majority state that they could do more, and would do particularly if others also took concerted and visible $\operatorname{action}^{25,26}$. Both qualitative and quantitative studies indicate that people in Britain believe the government should lead in combating climate change ${ }^{27,25}$, although the government is also one of the least trusted sources with respect to climate change issues, whilst scientists and environmental groups are the most trusted ${ }^{23}$. Trust is a factor that has been repeatedly found to influence perceptions and responses to risk issues $^{28,29}$. We note that low trust of the government in dealing with climate change risks need not indicate complete rejection of government policies and information. Poortinga and Pidgeon ${ }^{30}$ postulate the existence of 'critical trust', a healthy type of distrust which refers to a continued reliance on an organisation to operate in a fair and expert manner whilst maintaining some scepticism and a vigilant scrutiny of operations.

\section{Attitudes towards energy sources}

Within Britain, and across Europe, polls indicate that renewable energy sources tend to be the most favoured of different energy sources, while fossil fuels are less favoured, and nuclear energy is least favoured and opposed by many ${ }^{31,15}$. Environmental groups, such as Greenpeace, have been particularly vocal in their support of renewable energy and evidence indicates that environmentally concerned individuals are most willing to pay extra in order to obtain 'green' electricity tariffs that use energy from renewable sources ${ }^{32}$. Further factors that drive evaluations of different renewables tend to be fairly specific to the source and the individual. For example some people consider wind farms to have a negative visual impact ${ }^{33}$ whilst solar power is often considered particularly expensive ${ }^{34}$. Solar energy and wind energy tend to be viewed most favourably of all renewables. Slightly less favourable attitudes are demonstrated towards hydroelectric and biomass sources, which may be due to a lack of familiarity ${ }^{35}$.

Of the fossil fuels, natural gas tends to be perceived most favourably followed by oil and coal ${ }^{15}$. Disadvantages of fossil fuels relate to air pollution and its contributions to climate change. There is also widespread concern amongst the public that fossil 
fuels are running out ${ }^{36}$. Interestingly, however, there is some evidence that the potential for carbon capture and storage (CCS) may increase the attractiveness of the continued use of traditional fossil fuels ${ }^{37}$.

Nuclear power has been a particular focus of public concern and opposition. It has in the past been associated with potential adverse effects on the environment, including the accidents at Three Mile Island and Chernobyl, and indeed anti-nuclear sentiments were a main unifying cause that inspired the development of many environmentalist groups ${ }^{8}$. There are also ongoing public health concerns relating to nuclear power, such as increased cancer risks for those living in close proximity to nuclear plants ${ }^{38}$, and problems with the long-term disposal of nuclear waste ${ }^{39}$. For a period of 30 years at least there has been widespread public concern about the risks of nuclear energy in many countries $40,41,42$. Anti-nuclear opinions expressed by the British public are broadly similar to views in the $\mathrm{US}^{43}$ and in most other EU countries, where until very recently significant majorities have opposed the use of nuclear power, primarily for environmental and safety reasons ${ }^{13}$. However, public views on nuclear energy do now appear to be changing and levels of support for nuclear power have increased somewhat in the past few years ${ }^{42,44}$. A 2008 Eurobarometer survey found, asking a very general question ${ }^{\text {ii }}$, that fully $50 \%$ of the population sample in the UK were 'in favour of energy production by nuclear power stations' compared to only $44 \%$ in $2005^{44}$, with considerable variation also evident between countries. The same Eurobarometer survey indicates that support has increased similarly across Europe.

The reframing of nuclear power as a 'green' technology may have contributed to its more positive evaluation by people. Research that explicitly examined the impact of framing nuclear power as a potential method of mitigating climate change found that higher proportions of the British public are prepared to accept nuclear power if they believe that this does help to mitigate climate change ${ }^{10}$. However, the researchers argued that this represents a 'reluctant acceptance', with the vast majority of respondents also maintaining a clear preference for renewable energy sources over nuclear. In qualitative work it has been found that individuals consider both climate change and nuclear power to be problematic, and complex responses to the framing of nuclear as a method of mitigating climate change indicate that such a risk-risk tradeoff is not universally accepted ${ }^{9}$.

To date, research examining evaluations of different energy options has been primarily descriptive. So, although nuclear power has traditionally been viewed quite negatively, and the recent reframing of nuclear power as a low carbon energy source may have impacted these views, there is little research that examines this possibly changing relationship.

\section{Environmental values and worldviews}

Modern environmental movements emerged in the post World War II period, spurred on by opposition to both nuclear energy and the atomic bomb ${ }^{45}$. The 1970 s saw the

\footnotetext{
ii The comparisons of the results of different questions has to be treated with considerable care. As Rosa (2007) points out the absolute extent of 'opposition' or 'support' to nuclear power is highly dependent upon the precise question being asked. More reliable comparisons are where repeated questions appear on the same poll across time.
} 
institutionalisation of environmental issues, with the development of legislation and the formation of environmentally focused NGOs, political parties, and government departments. At the same time, social sciences began to study the environmental concern that was developing. Surveys of the time indicated that the majority of the general public in most (Western) countries were concerned about the environment ${ }^{46}$.

The development of environmental concern was documented within environmental sociology with the identification of an emerging and new ecological worldview, known as the New Ecological Paradigm, gaining ground over the previously dominant anthropocentric Human Exemptionalist Paradigm ${ }^{47}$. The accompanying New Ecological Paradigm scale that was developed became a widely used measure of proenvironmental orientation and helped to stimulate further research in this area ${ }^{48}$. In a similar vein, cultural theory identifies environmental concern within a specific cultural bias, or worldview that some individuals are considered to hold. Cultural theory ${ }^{49,50}$ identifies different types of cultural bias that are defined according to the extent that they are individually or group orientated, and to the extent that individuals believe that rules are required in order to control behaviour. In particular, an egalitarian worldview is associated with the idea that nature is a fragile and precarious system which must be protected and with a dislike of technology, believing that technology is a major source of environmental problems ${ }^{51}$. Ellis and Thompson ${ }^{52}$ found that members of environmental groups were more supportive of an egalitarian bias and less supportive of other worldviews than the general population. Further to this, the egalitarian worldview has been related to higher levels of risk perception of nuclear power plants $^{53}$ and to a greater likelihood of associating negative images with a nuclear waste repository than other worldviews ${ }^{54}$. Surprisingly, there is less evidence on the relationship between evaluations of nuclear power and the construct of environmental concern more generally, with many researchers appearing to assume a negative association between environmental concern and evaluations of nuclear power without directly testing the empirical relationship. A relatively small number of published studies do test this ${ }^{\text {iii }}$, and indicate a reliable negative relationship between these two constructs $55,56,57,58$.

Throughout the 1970s and 1980s, nuclear power remained a main focus of the environmental movement. However, towards the end of this period and within the following decades, the issue first described as global warming, now more accurately known as climate change, developed and became more important within the environmental movement. Climate change has now been taken up by individuals, organisations and governments well beyond the traditional environmental groups and stakeholders $^{59}$. Given this, we would suggest that arguments linking the use of nuclear power and climate change mitigation pose a dilemma for environmentally concerned individuals. On the one hand traditional concerns about nuclear power are likely to remain strong, while on the other the rising concerns about climate change require

\footnotetext{
iii Unpublished data analyses for a major survey of perceptions of nuclear power in both France and the United States conducted in the early 1990s indicated a negative correlation between the more specific construct of concern for climate change and evaluations of nuclear power (Slovic, P., personal communication, $28^{\text {th }}$ October, 2008).
} 
radical solutions that span behaviour, technology, and social organisation, including nuclear power as a potential low-carbon source of energy. Although research on public opinion on environmental concern, concern about climate change, and evaluations of nuclear power is available, it remains unclear how they are related to each other. This paper sets out to explore the relationships between general environmental concern, concern about climate change, and perceptions of nuclear energy and other energy sources in more detail.

\section{British views on climate change and energy choices: research aims and data collection}

The current study explores associations between perceptions of climate change, general environmental concern, and evaluations of different energy sources, with specific aims to:

- Examine the relationship between climate change perceptions and evaluations of different energy sources, in particular nuclear power.

- Examine whether general environmental concerns underlie the relationship between perceptions of climate change and evaluations of different energy sources.

- Examine participants' agreement with the idea that nuclear power may help to mitigate climate change and how agreement with this idea may relate to evaluations of nuclear power.

Based on the literature discussed above we hypothesise that general environmental concerns will be negatively related to evaluations of nuclear power and fossil fuels, but positively related to evaluations of renewables. We further suggest that concern about climate change will be negatively associated with support for nuclear power, and that this is mainly due to the influence of general environmental concern. In other words, people who are concerned about the environment are also concerned about climate change and (the risks of) nuclear power. This would mean that, despite some evidence that associations with climate change may increase support for nuclear power ${ }^{10,27}$, both climate change concern and opposition to nuclear power are still central to general environmental concerns. Environmental concern is predicted to have a similar impact on the relationship between climate change concern and fossil fuels and renewables. We hypothesise that climate change concern will be negatively related to support for fossil fuels and positively related to support for renewables. Further to this, we suggest that only a minority of respondents will agree with the idea that using nuclear power can help to mitigate climate change but those who do are likely to be significantly more positive towards nuclear power than those who do not.

\section{METHODS AND DATA}

A nationally representative quota sample of 1491 individuals aged 15 years and over was surveyed by the market research company Ipsos-MORI, who presented the survey as examining the views of the British nation on various issues. Respondents were interviewed in their own homes in 257 sampling points across England, Wales, and Scotland between 1 October and 6 November 2005. Sample demographics were generally representative of the UK and consisted of $48 \%$ men and $52 \%$ women. 
The survey questionnaire consisted of 139 items which measured perceptions of a range of issues relating to the environment, climate change, and energy sources. Questions were informed by the academic literature and previous polling studies and were subject to extensive stakeholder consultation with individuals who held a range of opinions on the energy debate including people from within academia, environmental NGOs, energy industries, and government. Details of the survey and responses to all items have previously been reported ${ }^{11}$ as has an analysis of the impact of framing ${ }^{10}$.

Questions analysed in this paper concern evaluations of different energy sources, perceptions of climate change, environmental concern, and the relationship between the use of nuclear power and climate change mitigation. Evaluations were specifically examined through the question, 'How favourable or unfavourable are your overall opinions or impressions of the following energy sources for producing electricity currently?' Responses were recorded for eight energy sources: biomass, coal, gas, hydroelectric power, nuclear power, oil, sun/solar power, and wind power on a fivepoint scale marked from 'Very favourable' to 'Very unfavourable'.

Perceptions of climate change were evaluated with a series of questions and statements which assessed concern, acceptability, involvement, ambivalence, and trust in the management of climate change (see Table 1 for details of questions and response scales). In addition, environment concerns were evaluated through the question, 'How concerned, if at all, are you about each of the following issues?' Responses were recorded for 13 different environmental issues, including air pollution, household waste disposal, and pollution of rivers, lakes, and seas on a four-point scale marked from 'Very concerned' to 'Not at all concerned'.

Respondents were asked directly about their perceptions of the link between nuclear power and climate change mitigation using the question, 'To what extent do you agree or disagree that using the following energy sources to generate electricity can help prevent climate change?' Nuclear power was one of the response options. Responses were recorded on a five point scale marked from 'Strongly agree' to 'Strongly disagree'. For all questions and statements, respondents were provided with a 'No opinion' or 'Don't know' option'.

\footnotetext{
iv Responses coded as 'don't know' or 'no opinion' were deleted listwise; numbers of responses were too small to carry out any meaningful comparisons.
} 


\section{Table 1: Questions assessing constructs relating to perceptions of climate change and reliabilities for each construct}

ConstructQuestions assessing constructReliability (Cronbach's alpha)

\begin{tabular}{ll}
\hline Concern & 'How concerned, if at all, are you about each \\
& of the following issues? \\
& One option: Climate change, sometimes referred to \\
& as global warming' (Not at all concerned - Very concerned; \\
& 4 point scale) \\
\hline Acceptability & 'There are a lot of good things about climate change.' \\
& (Strongly disagree - Strongly agree; 5 point scale) \\
& 'There are benefits to people in Britain from climate change.' \\
& (Strongly disagree - Strongly agree; 5 point scale) \\
& 'There are risks to people in Britain from climate change.' \\
& (Strongly agree - Strongly disagree; 5 point scale) \\
& 'There are a lot of bad things about climate change.' \\
& (Strongly agree - Strongly disagree; 5 point scale) \\
& Overall how do you feel about climate change? \\
& (Very negative - Very positive; 5 point scale) \\
& From what you know or have heard about climate change, \\
& on balance, which of these statements, if any, \\
& most closely reflects your own opinion? \\
& (Risks outweigh benefits - Benefits outweigh risks; \\
& 5 point scale) \\
\hline 'I have mixed feelings about climate change.' \\
(Strongly disagree - Strongly agree; 5 point scale)
\end{tabular}

\section{RESULTS}

\section{Evaluations of energy sources}

Respondents' mean evaluations of each energy source are presented in Figure 1. Renewable energy sources were viewed the most positively, followed by traditional fossil fuels, and then by nuclear power, which was viewed the most negatively of all energy sources examined. Scores were then combined for renewable energy sources (solar, wind, hydroelectric, and biomass) and fossil fuels (gas, oil, and coal), by taking 
the mean of the evaluations of the individual energy types, to facilitate further comparative analyses. Internal reliability of these scales were examined using Cronbach's alpha and biomass was subsequently removed from the renewable evaluation scale as responses to this energy source were considerably different from the responses to the others ${ }^{\mathrm{v}}$; the remaining renewable energy sources had an acceptable scale reliability ${ }^{\mathrm{vi}}$ of 0.64 . Reliability of the fossil fuel evaluation scale was good with a Cronbach's alpha of 0.76 .

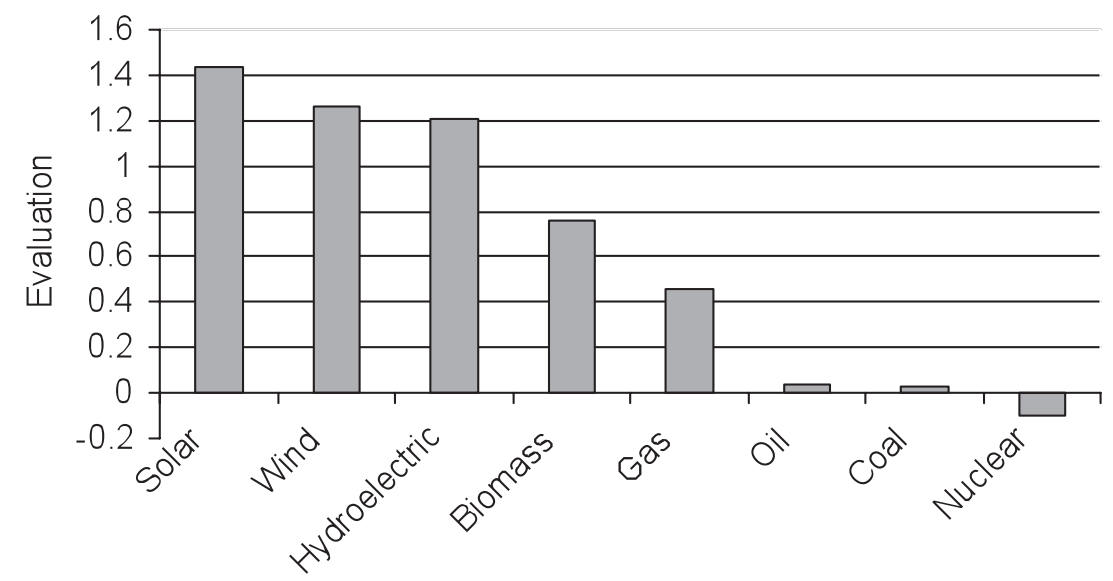

Energy sources

Figure 1. Figure 1 - Mean evaluations of energy sources. Evaluations were made on a five point rating scale scored so that $-2=$ very unfavourable, $+2=$ very favourable.

One-sample t-tests indicated that renewable energy sources, and fossil fuels were evaluated positively, $M \mathrm{~s}=1.30(S D=0.67), t(1463)=74.48, p<0.001$ and $0.17(S D$ $=0.89), \mathrm{t}(1447)=7.52, p<0.001$, respectively. Evaluations of nuclear power were negative, $M=-0.10(S D=1.25), t(1384)=-2.86, p<0.01$. A repeated measures ANOVA indicated that evaluations of renewable energy sources, fossil fuels, and nuclear power were significantly different from one another $(F(2,1446)=1003.62, p$ $<0.001)$. Follow-up t-tests indicated that evaluations of renewable energy sources were significantly more positive than fossil fuels $(p<0.001)$, and nuclear power $(p<$ 0.001). Fossil fuels were also evaluated as significantly more positive than nuclear power $(p<0.001)$. Interestingly, standard deviations demonstrate that agreement amongst respondents was highest for renewables, lower for fossil fuels, and that there was quite a lot of variance in evaluations of nuclear power; so there is a greater range of opinion on nuclear power than for other energy sources.

\footnotetext{
${ }^{v}$ Evaluations of biomass displayed a different pattern of variance to evaluations of other renewables examined lowering the reliability of the scale. This may be because people are less knowledgeable and familiar with biomass ${ }^{41}$.

vi The reliability of the scale for evaluations of renewables is slightly lower than is normally considered acceptable (0.70). We note that this could be improved by eliminating evaluations of hydroelectric power from this scale; this would increase scale reliability to 0.68 . However, when analyses are carried out using this alternative scale there are only very minor differences, leading us to use the more inclusive scale
} 


\section{Perceptions of climate change}

Measures used to examine different perceptions relating to climate change are summarised within Table 1. Ambivalence was assessed with a direct question whilst other constructs were represented by several questions combined. All scales were coded so that higher numbers indicate more positive values of the constructs, e.g. more ambivalent, more involved (see Figure 2, which displays means of each construct, except concern about climate change due to differences in the scale used). Respondents displayed a fairly high level of concern about climate change, $M=3.27$ $(\mathrm{SD}=0.79)$, obtained on a scale from 1 to 4 . Our sample perceived climate change as unacceptable and the majority of respondents did not place trust in the current management of climate change issues. Respondents felt fairly involved with climate change issues and were neutral with regard to their levels of ambivalence. Questions on concern about various environmental issues, e.g. air pollution, household waste (not including climate change and nuclear power) formed a reliable scale with Cronbachs alpha of 0.85 . This provided a measure of environmental concern, $M=$ 3.11 ( $\mathrm{SD}=0.48)$, obtained on a scale from 1 to 4 .

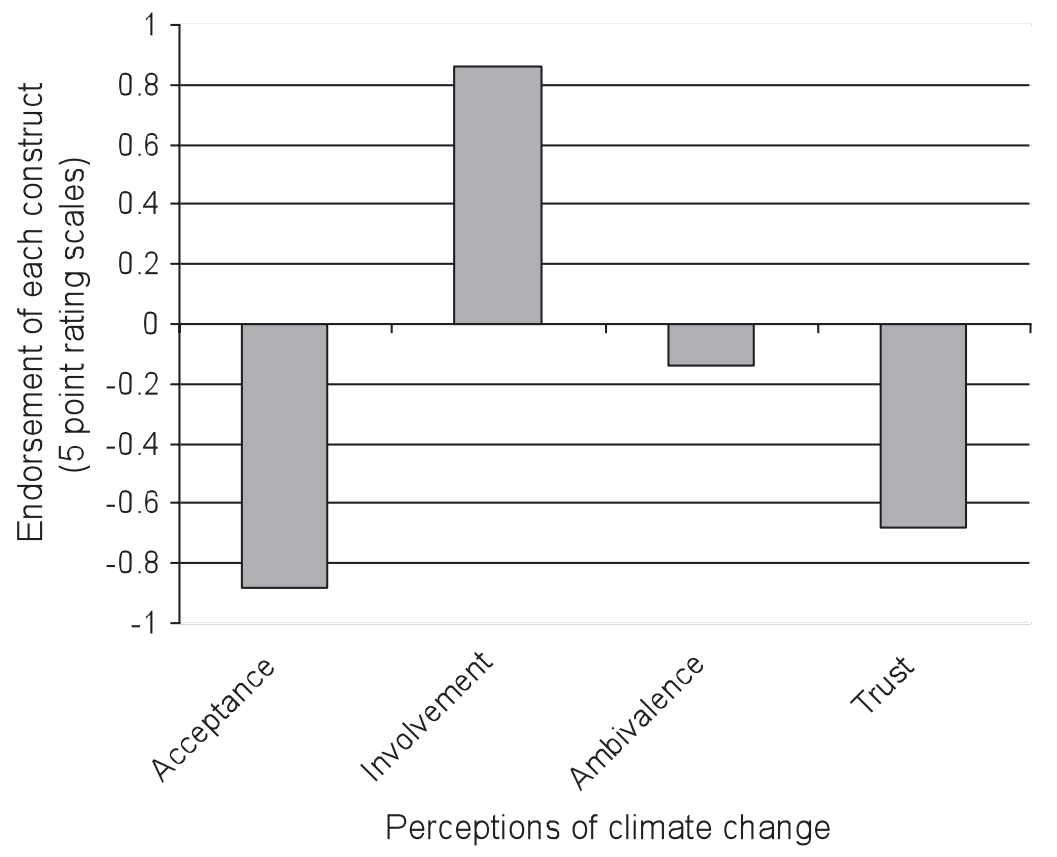

Figure 2 - Perceptions relating to climate change. Endorsement of each construct is measured on a five point rating scale scored so that $-2=$ low endorsement, $+2=$ high endorsement. Concern about climate change was evaluated using a different scale to the perceptions of climate change depicted here and therefore is not included within this figure. 


\section{Correlations between climate change perceptions, environmental concern and evaluations of energy sources}

The relationship between perceptions of climate change, environmental concern and evaluations of different types of energy sources were explored with unadjusted correlations, see Table 2. Relationships between climate change perceptions, environmental concerns and evaluations of energy sources were fairly similar for fossil fuels and nuclear power but differed for renewables. People who were negative towards nuclear power and fossil fuels tended to be more concerned about climate change and the environment. Those who were more positive towards nuclear power and fossil fuels tended to be more accepting of climate change, trusted in the management of climate change and were more ambivalent about climate change. These relationships were directly reversed for renewables. So people who were positive towards renewables, tended to be concerned and involved with climate change and to be environmentally concerned. They were also less accepting and less ambivalent about climate change, and less trusting of the management of climate change.

Table 2: Unadjusted correlations and adjusted beta values between climate change perceptions, environmental concern and evaluations of different types of energy

\begin{tabular}{|c|c|c|c|c|c|c|}
\hline \multirow{2}{*}{$\begin{array}{l}\text { Environmental } \\
\text { concern and } \\
\text { perceptions of } \\
\text { climate change } \\
\end{array}$} & \multicolumn{2}{|c|}{ Renewables $^{\mathrm{a}}$} & \multicolumn{2}{|c|}{ Fossil Fuels $^{\mathrm{b}}$} & \multicolumn{2}{|c|}{ Nuclear Power ${ }^{\mathrm{c}}$} \\
\hline & $\mathrm{r}$ & $B$ & $\mathrm{r}$ & $\beta$ & $\mathrm{r}$ & $\beta$ \\
\hline $\begin{array}{l}\text { Environmental } \\
\text { concern }\end{array}$ & $0.28 * * *$ & $0.20 * * *$ & 0.02 & $0.09 * *$ & $-0.12 * * *$ & $-0.09 * *$ \\
\hline $\begin{array}{l}\text { Concern about } \\
\text { climate change }\end{array}$ & $0.20 * * *$ & -0.03 & $-0.08 * *$ & -0.02 & $-0.10 * * *$ & 0.03 \\
\hline $\begin{array}{l}\text { Acceptability of } \\
\text { climate change }\end{array}$ & $-0.18 * * *$ & -0.02 & $0.20 * * *$ & $0.13 * * *$ & $0.24 * * *$ & $0.22 * * *$ \\
\hline $\begin{array}{l}\text { Ambivalence } \\
\text { towards climate } \\
\text { change }\end{array}$ & $-0.15 * * *$ & $-0.06^{*}$ & $0.15^{* * * *}$ & $0.08 * *$ & $0.10 * * *$ & -0.01 \\
\hline $\begin{array}{l}\text { Involvement with } \\
\text { climate change }\end{array}$ & $0.27 * * *$ & $0.16^{* * *}$ & $-0.11 * * *$ & 0.02 & $-0.10 * * *$ & $0.09 * *$ \\
\hline $\begin{array}{l}\text { Trust in regulation } \\
\text { of climate change }\end{array}$ & $-0.15 * * *$ & -0.02 & $0.19 * * *$ & $0.13 * * *$ & $0.23 * * *$ & $0.16^{* * *}$ \\
\hline
\end{tabular}

For Regressions, ${ }^{a} R^{2}=0.11, p<0.001{ }^{b} R^{2}=0.06, p<0.001{ }^{c} R^{2}=0.09, p<0.001$

Note: ${ }^{*} p<0.05,{ }^{* *} p<0.01,{ }^{* * *} p<0.001$

Perceptions of climate change and environmental concerns were subsequently regressed against evaluations of different types of energy sources using multiple linear regressions with a forced method of entry, see Table 2. 
This allows us to examine which variables were most strongly related to evaluations of energy sources and highlights which variables interact with each other when included within the same analysis. Although there is clearly some overlap between the different climate change variables, collinearity was not problematic with tolerance statistics varying between 0.5 and 0.8 (less than 0.2 is considered problematic $^{60}$ ).

A clear finding here was that environmental concern remained one of the strongest predictors of evaluations overall (being related to positive evaluations of renewables and fossil fuels and negative evaluations of nuclear power) whilst concern about climate change appeared to be outweighed by the other factors included in the analysis. With respect to renewables, when all variables were examined simultaneously, only environmental concern and involvement with climate change issues were significantly related to evaluations, outweighing relationships with concern about climate change, acceptability of climate change and trust in the management of climate change.

For nuclear power, when all variables were examined within the same analysis, environmental concern, acceptability and involvement with climate change and trust in the regulation of climate change retained significant relationships with evaluation, whilst concern about climate change and ambivalence towards climate change which were previously significant, here were outweighed by the other relationships. Interestingly, once other factors had been accounted for, involvement with climate change issues became positively related to evaluations of nuclear power, a relationship that is negative when unadjusted correlations are examined.

For evaluations of fossil fuels, when all variables were examined within a regression equation, environmental concern, acceptability of climate change issues, ambivalence towards climate change and trust in regulation of climate change remained significant. Concern about climate change here became non significant (as already noted) as did involvement with climate change. It is notable that when all variables were analysed together, environmental concern became positively related with evaluations of fossil fuels, in contrast to the non significant relationship noted between these variables within unadjusted correlations.

\section{Confounding by environmental concern}

In order to test our hypothesis that the associations between climate change concern and the evaluation of different energy sources are due to environmental concern, we ran a series of third variable models ${ }^{61}$. Confounding ${ }^{\text {vii }}$ can be said to occur if a) there is a significant relationship between concern about climate change and environmental concern, and b) environmental concern is significantly related to the evaluations of the energy source (over and above effects of concern about climate change). These relationships are illustrated in Figures $3 \mathrm{a}, \mathrm{b}$ and $\mathrm{c}$, where the strength of the confounding effect in each case is tested using a Sobel test. Environmental concern partially explains the negative relationship between concern about climate change and evaluations of nuclear power, $\mathrm{z}=2.94, \mathrm{p}<0.01$ (see Figure $3 \mathrm{a}$ ), as well as the positive

\footnotetext{
vii We use the term 'confounding' rather than 'mediation' here, even though the two are examined using the same analytic procedure, because confounding does not imply a causal relationship amongst the variables.
} 
relationship between concern about climate change and evaluations of renewables, $\mathrm{z}$ $=7.54, \mathrm{p}<0.001$ (see Figure $3 \mathrm{~b}$ ). Interestingly, the negative relationship between concern about climate change and evaluations of fossil fuels increased when controlling for environmental concern indicating a suppression effect, $\mathrm{z}=2.81, \mathrm{p}<$ 0.01 , see Figure $3 c$ (see MacKinnon et al. ${ }^{61}$ for a further discussion of suppression effects). So, while environmental concern has a positive direct association with evaluations of fossil fuels it also indirectly decreases the negative association between concerns about climate change and evaluations of fossil fuels.

a)

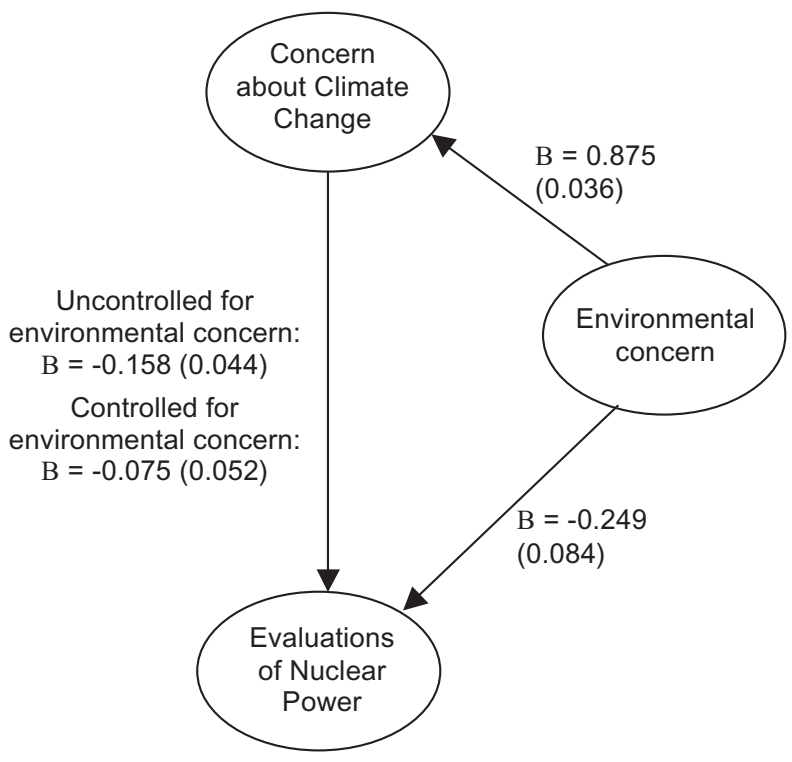

b)

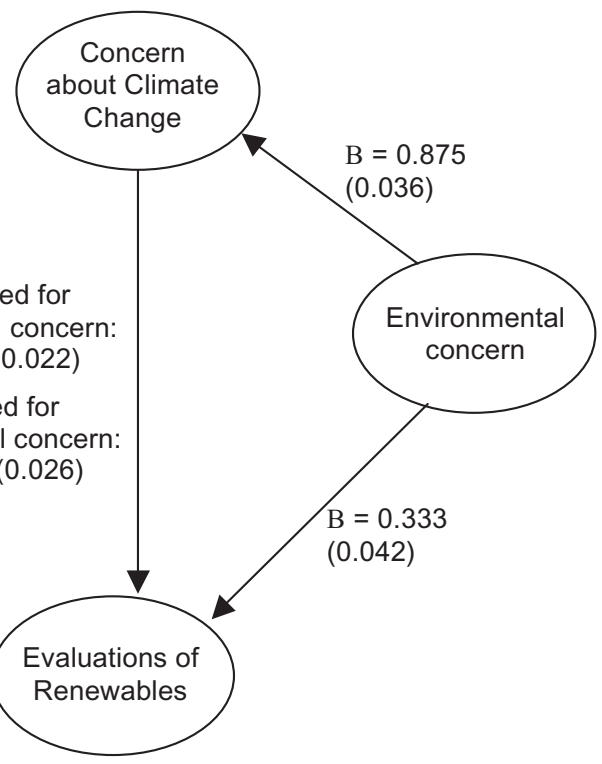


c)

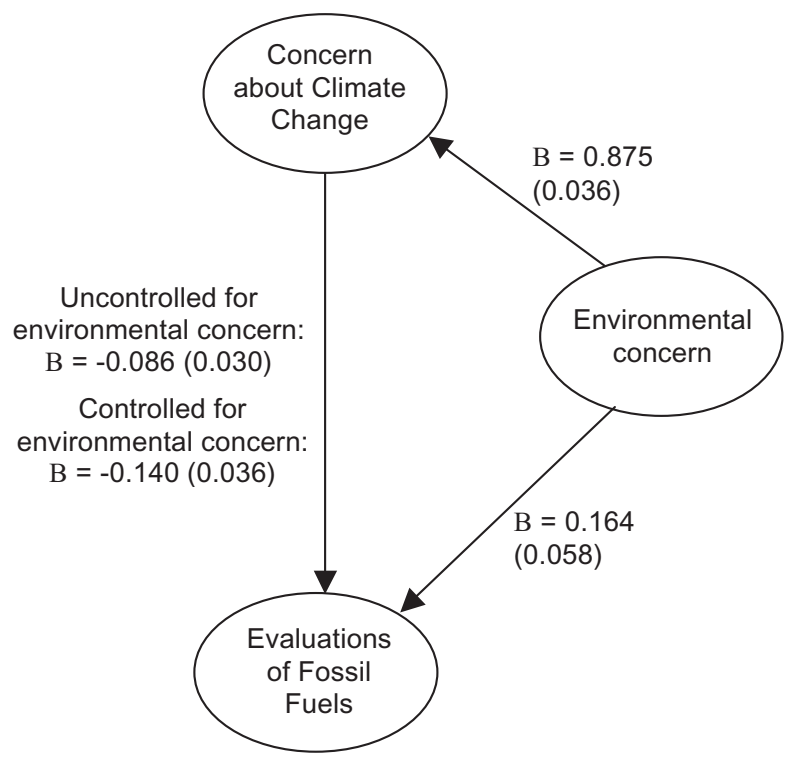

Figure 3. Environmental concern as a confounder of the relationship between concern about climate change and evaluations of energy source. Figures presented are unstandardised beta coefficients (B) obtained from regressions, along with the standard errors for these figures.

Data were also obtained on whether respondents agreed or disagreed that the use of nuclear power helped to prevent climate change. With regards to helping to prevent climate change, altogether $37.2 \%$ of respondents thought that nuclear power did help, $35.6 \%$ thought that nuclear power did not help, $20.4 \%$ neither agreed nor disagreed with this, and $6.8 \%$ said that they did not know or did not want to respond to that question. Notably, respondents who believed that nuclear power helps to prevent climate change displayed significantly more positive evaluations of nuclear power than those who did not believe that nuclear power can help to prevent climate change, $\mathrm{Ms}=0.62(\mathrm{SD}=1.05)$ versus $-0.81(\mathrm{SD}=1.15), \mathrm{t}(1044)=-21.16, \mathrm{p}<0.001)$. In addition, participants who believed that nuclear power helps to prevent climate change had a lower concern for climate change than those who did not believe that nuclear power helps to prevent climate change, $M \mathrm{~s}=3.18(\mathrm{SD}=0.68)$ versus $3.35(\mathrm{SD}=$ $0.63), \mathrm{t}(1082)=4.25, \mathrm{p}<0.001)$. Further to this these same participants, who believed that nuclear power can help to mitigate climate change, also had a lower concern for the environment than those who did not believe this, $M \mathrm{~s}=3.05$ ( $\mathrm{SD}=$ $0.46)$ versus $3.25(\mathrm{SD}=0.44), \mathrm{t}(1083)=7.52, \mathrm{p}<0.001$, see Figure 4. 


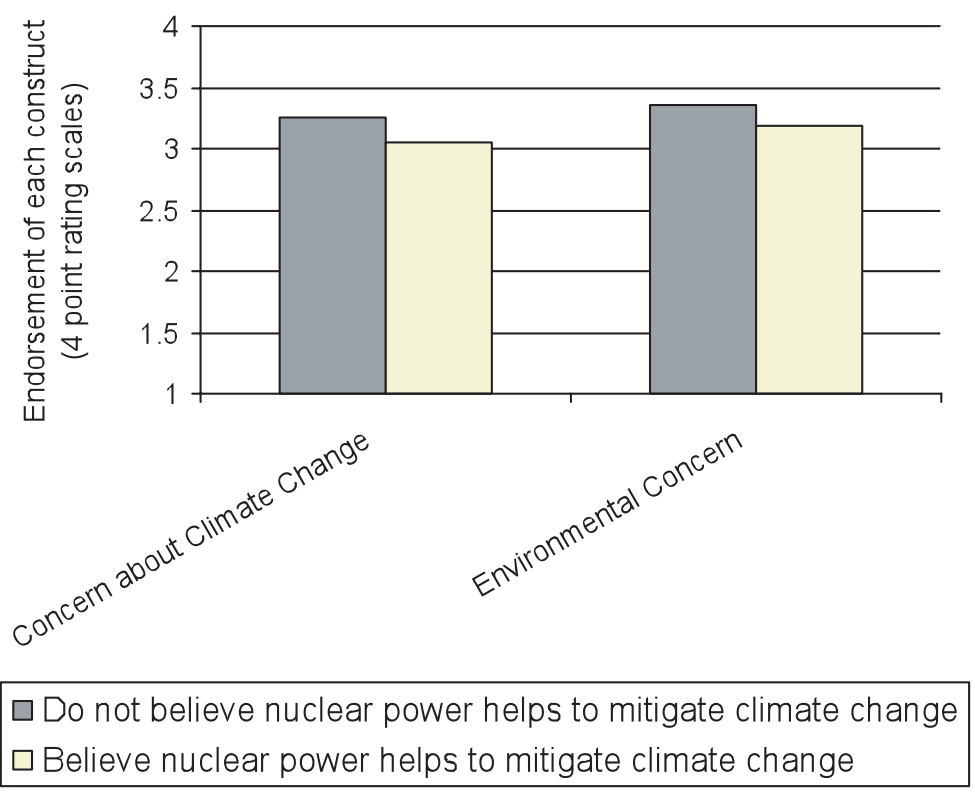

Figure 4. Mean concern about climate change and the environment for respondents who do and do not link nuclear power with climate change mitigation. Evaluations were made on a four point rating scale scored so that $1=$ not at all concerned, $4=$ very concerned.

\section{DISCUSSION}

In line with previous research ${ }^{15}$ respondents evaluated renewable energy sources most positively, followed by fossil fuels, whilst nuclear power was evaluated most negatively. In addition, whilst people tended to agree on evaluations of renewables and fossil fuels, there was much more variation in evaluations of nuclear power, reflecting the controversial nature of the technology and the debates which still surround it. Concern about climate change and environmental concern were negatively related to evaluations of nuclear power and positively related to evaluations of renewables. Both of these findings are in line with historical environmentalist beliefs and discourses, and previous research on the relationship between environmental beliefs and nuclear power ${ }^{57,58}$. Only a minority of people considered nuclear power to be a method for mitigating climate change, whilst people who did not think that nuclear power can help to prevent climate change were also those who are most concerned about the environment and about climate change. It appears then that those who are most concerned about the specific issue of climate change also reflect the philosophy of traditional environmentalist movements in maintaining an anti-nuclear stance.

Previous research has suggested some evidence for increased acceptance of nuclear power when it is explicitly framed alongside climate change concerns ${ }^{9,10}$. The difference in the present analysis is that nuclear power is not presented explicitly as a potential method of mitigating climate change. We conclude from this that while 
acceptance may be higher when framed as a possible method of mitigating climate change, most people are unlikely to spontaneously evaluate nuclear power in this way.

\section{Perceptions of climate change, and levels of environmental concern}

Our respondents reported themselves to be highly concerned about both the environment and climate change, again supporting previous research ${ }^{20,13}$. We note, however, that our survey had a specific focus on climate change and energy policy issues and that previous research has noted that the relative importance of these issues may be viewed differently when presented alongside other salient issues such as unemployment or the economy ${ }^{14,15,16}$. In addition, our participants felt fairly involved with climate change, did not believe it to be an acceptable risk, and did not trust the government to manage climate change.

\section{Relationships between perceptions of climate change, environmental concerns, and evaluations of energy sources}

Perceptions of climate change and environmental concerns were related to evaluations of energy sources in similar ways. As hypothesised, those participants who were environmentally concerned, as well as those who were concerned and involved with climate change, were generally more positive about renewables and more negative about nuclear power and fossil fuels supporting previous research ${ }^{32}$. In contrast, those who were more accepting of climate change, ambivalent about climate change, and trusting in the management of climate change issues (a smaller proportion in our sample) tended to be more positive about nuclear power and fossil fuels and less positive towards renewables.

A slightly different pattern of results emerges, however, when variables are simultaneously included in a regression equation. Here we can examine the relative importance of factors measured in relation to evaluations of different energy sources. In particular, for evaluations of renewables, the degree to which people are prepared to accept climate change and trust in the government to regulate climate change are outweighed, and encompassed, by other relatively more important factors, however, these factors remain important for evaluations of fossil fuels and nuclear power. Evaluations of fossil fuels and nuclear power are both linked with high levels of acceptance of climate change and trust in the management of climate change issues.

Also of note is the relationship between involvement with climate change and evaluations of nuclear power. Without considering any other factors, those individuals who are more involved with climate change tend to be more negative towards nuclear power. However, when perceptions of climate change and environmental concerns are included within the same analysis, involvement with climate change is positively associated with support for nuclear power. That is, if perceptions of climate change and environmental concerns are taken into account, those who are more involved with climate change tend to be more positive towards nuclear power. This suggests that the specific relationships between variables are different for different population subsets amongst our sample; with some who are involved with the issue of climate change indeed being receptive to the idea that nuclear power may help to mitigate climate change while others (most likely because of pre-existing environmental beliefs) are not. 
Notably when perceptions of climate change and environmental concerns are included simultaneously in a regression equation, environmental concern remains a strong predictor of evaluations of each of the energy sources examined, whilst the importance of concerns about climate change is reduced. This indicates the pervasive importance of environmental concerns in relation to evaluations of energy sources. Supporting this, a third variable analysis demonstrates that the relationships observed between concerns about climate change and evaluations of nuclear power and renewables respectively were both partially explained by environmental concerns. This suggests that individuals' concerns about climate change and preferences for nuclear power and for renewables form part of a wider set of views regarding the environment. Findings are in line with previous research that theorises that a more general overarching belief system can, at least partially, account for related more specific attitudes towards nuclear power or other risk issues ${ }^{50,62,63}$. It appears that the links, historically identified in the literature, between environmental concerns and anti-nuclear sentiments remain a strong driving force on the attitudes of many. We conclude from this that attempts to reframe nuclear power as a method for mitigating climate change can only ever be partially successful in the short-term, and only with certain people, although a more interesting research question will be the extent to which the relationship between concerns about climate change and nuclear power may shift further, conditional upon changes in wider beliefs and discourses in environmental change and protection ${ }^{\text {viii }}$.

The relationship between participants' evaluations of fossil fuels and perceptions of climate change and the environment was more complicated. Ambivalence towards climate change was an important factor in relation to evaluations of fossil fuels and remained so even when all other factors were included in analyses indicating that people who had mixed feelings about climate change were more likely to be positive about fossil fuels. Interestingly, once people's perceptions of climate change issues were accounted for (and partialled out of analyses) the relationship between environmental concerns and evaluations of fossil fuels was positive. Conversely, the relationship between climate change and evaluations of fossil fuels became more negative when environmental concerns were accounted for within analyses. This indicates that fossil fuels may be viewed positively with regard to general environmental considerations (when climate change concerns are removed) and this may be, at least in part, attributable to the fact that fossil fuels are more traditional fuel sources that are more familiar to participants. From a climate mitigation perspective, evaluations of fossil fuels are clearly negative though, suggesting that increasing public discourses regarding the link between fossil fuels and climate change may be impacting public awareness.

\section{Future research}

The research presented here helps to develop and clarify our understanding of the relationship between perceptions of climate change, environmental concerns, and evaluations of different energy sources. Note that data used within analyses were

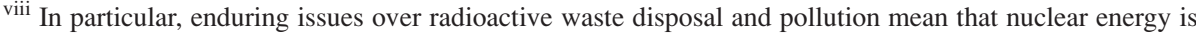
unlikely to ever gain the status of an environmentally benign technology
} 
gathered in 2005, however, and therefore it would be useful to re-examine these relationships in longitudinal analysis against new data. In particular, recent significant events including the UK's new Climate Change Bill ${ }^{64}$, the government white paper on Nuclear Power ${ }^{3}$ and consultation on public attitudes towards nuclear power ${ }^{4}$, and other related communications associated with the moves to develop existing nuclear sites in Britain $^{65}$, all have the potential to alter public perceptions further. Findings presented in this paper remain of interest however, both for historical and comparative purposes as well as for their theoretical value in examining the relationship between climate change concerns, environmental concerns, and evaluations of energy sources, considered here for the first time. We also acknowledge that data presented here were cross sectional and therefore the causality of relationships examined can not be inferred; further research using longitudinal or experimental designs would help to clarify this.

The analyses presented here explain a significant proportion of variance in evaluations of different energy sources; however a large amount of variance remains unexplained, perhaps unsurprisingly, as we focused solely on perceptions of climate change and the environment. Previous research has also identified the importance of structural issues, e.g. cost, as well as further personally relevant factors, including affective reactions, e.g. dread ${ }^{66}$, and implicit associations ${ }^{67}$ in relation to evaluations of different energy sources and future research would usefully examine the relative importance of these factors.

\section{CONCLUSIONS}

This paper provides the first comprehensive and contemporary exploration of the relationship between evaluations of different energy sources, perceptions of climate change, and environmental concern, using a representative survey of British adults in the autumn of 2005. Results indicate that people who are concerned about climate change are generally opposed to nuclear power and supportive of renewable energy sources. However, when taking into account other constructs, such as concern about climate change, involvement with climate change is positively linked with support for nuclear power, suggesting that some of those who feel involved with the issue of climate change are receptive to the idea that nuclear power may help to mitigate climate change. Overall though, concern about climate change and opposition to nuclear power appears to be firmly embedded in beliefs stemming from more traditional environmental worldviews. As suggested by other recent studies ${ }^{9,10}$, those who are willing to consider the idea, are likely to only reluctantly accept the trade-off outlined between climate change and nuclear power.

From an energy policy perspective this finding has implications for the re-framing of nuclear power as a low carbon energy source by the government, the nuclear industry, and some environmental commentators. Our findings imply that any public discussion or consultation ${ }^{4}$ which simply presents nuclear power alongside climate change, without an examination of the wider scope for alternative solutions to climate change, may be unduly restrictive for many people. Framing nuclear power solely within the context of climate change may also result in misconceptions and possibly further scepticism and mistrust ${ }^{68}$ regarding the motives for the further development of 
nuclear power. We suggest, in contrast, the need for a policy and public debate, where all energy options (including that of demand reduction ${ }^{69}$ ) are examined in the context of other energy futures and their wider impacts upon the environment and society.

\section{ACKNOWLEDGEMENTS}

This research was supported by Cardiff University, the University of East Anglia, and two successive grants from the Leverhulme trust awarded to the University of East Anglia (F/00 204/E) and to the Understanding Risk research group at Cardiff University (F/00 407/AG). with additional support from the UK economic and social research council (grant RES-152-25-1011).

\section{REFERENCES}

1. IPCC (2007). Climate Change 2007: Synthesis Report. Contribution Of Working Groups I, II, And III To The Fourth Assessment Report Of The Intergovernmental Panel On Climate Change. Geneva, Switzerland: IPCC.

2. DTI (2006). The Energy Challenge: Energy Review Report 2006. London: HM Government.

3. BERR (2008a). A White Paper On Nuclear Power. London: HM Government.

4. BERR (2008b). The Future Of Nuclear Power: Analysis Of Consultation Responses. London: HM Government.

5. Petroll, M. and Tweiten, B. (2007). US plans for new nuclear power plants: Who, what, how, why? International Journal for Nuclear Power, 52, 230.

6. Rosa, E.A., (2007). The Public Climate For Nuclear Power: The Changing Of Seasons, Paper presented at the Howard H. Baker Jr. Center for Public Policy Conference: The Role of Nuclear Power in Global and Domestic Energy Policy. Woodrow Wilson International Center for Scholars, Washington, DC (3-4 October, 2007).

7. Guldner, R. (2007). Worldwide perspectives of nuclear power use. International Journal for Nuclear Power, 52, 484.

8. Welsh, I. (2000). Mobilising Modernity: The Nuclear Moment. London and New York: Routledge.

9. Bickerstaff, K., Simmons, P. and Pidgeon, N. (2008). Constructing responsibility for risk(s): Negotiating citizen-state relationships. Environment and Planning A, 40, 13121330 .

10. Pidgeon, N. F., Lorenzoni, I., and Poortinga, W. (2008). Climate change or nuclear power - No thanks! A quantitative study of public perceptions and risk framing in Britain. Global Environmental Change, 18, 69-85.

11. Poortinga W., Pidgeon, N.F. and Lorenzoni, I. (2006). Public Perceptions Of Nuclear Power, Climate Change And Energy Options In Britain: Summary Findings Of A Survey Conducted During October And November 2005. Technical Report Understanding Risk Working Paper 06-02). Norwich: Centre for Environmental Risk. Available at http://www.tyndall.ac.uk/publications/energy futures full report.pdf 
12. OST/MORI (2004). Science In Society - Findings From Qualitative And Quantitative research, Conducted For The Office Of Science And Technology, Department Of Trade And Industry. London, UK: MORI Social Research Institute.

13. Eurobarometer (2007). Attitudes On Issues Related To EU Energy Policy - Analytic Report (Flash Eurobarometer 206a). Europe: European Commission.

14. Poortinga, W. and Pidgeon, N. (2003a). Public Perceptions Of Risk, Science And Governance: Main Findings Of A British Survey Of Five Risk Cases. Norwich: Centre for Environmental Risk.

15. Eurobarometer (2006). Energy Technologies: Knowledge, Perception, Measures (EUR 22396). Europe: European Commission.

16. Norton, A. and Leaman, J. (2004). The Day After Tomorrow: Public Opinion On Climate Change. London, UK: MORI Social Research Institute.

17. Leiserowitz, A. (2006). Climate change risk perception and policy preferences: The role of affect, imagery, and values. Climatic change, 77, 45-72.

18. Lorenzoni, I. (2003). Present Choices, Future Climates: A Cross-Cultural Study Of perceptions In Italy And In The UK. Doctoral Thesis, School of Environmental Sciences, University of East Anglia, Norwich, UK.

19. Zwick, M. M. and Renn, O. (Eds), (2002). Perception And Evaluation Of Risks. Findings Of The Baden-Wurttemberg Risk Survey 2001. Joint working report by the Centre of Technology Assessment in Baden-Wurttemberg and the University of Stuttgart, Sociology of Technologies and Environment, Germany.

20. Lorenzoni, I. and Pidgeon, N. F. (2006). Public views on climate change: European and USA perspectives. Climatic Change, 77, 73-95.

21. Kirby, A. (2004). The Climate Change Special Poll. Accessed: 30 April 2008. URL:

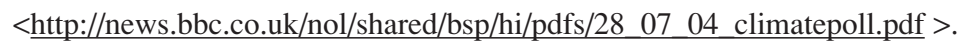

22. Palutikof, J. P., Agnew, M. D. and Hoar, M. R. (2004). Public Perceptions Of Unusually Warm Weather In The UK: Impacts, Responses And Adaptations. Climate Research, 26, 43-59.

23. AccountAbility and Consumers International (2007). What Assures Consumers On Climate Change? Switching On Citizen Power. Accessed: 30 April 2008. URL: < http://www.accountability21.net/pubslist.aspx?id=808 >.

24. Energy Saving Trust (2007). Green Barometer: Measuring Environmental Attitude. London: Energy Saving Trust.

25. MORI (2007). Climate Change Questionnaire: Public Affairs Monitor. UK: MORI Social Research Institute.

26. Lorenzoni, I., Nicholson-Cole, S. Whitmarsh, L. (2007) Barriers perceived to engaging with climate change among the UK public and their policy implications. Global Environmental Change, 17(3-4), 445-459

27. Bickerstaff, K., Lorenzoni, I., Pidgeon, N. F., Poortinga, W. and Simmons, P. (2008). Reframing nuclear power in the UK energy debate: Nuclear power, climate change mitigation and radioactive waste. Public Understanding of Science, 17, 145-169. 
28. Cvetkovich, G. and Lofstedt, R. (1999). Social Trust And The Management Of Risk. London: Earthscan.

29. Rohrmann, B. and Renn, O (2000). Risk perception research - An introduction. In Renn, O. and Rohrmann, B. (eds.), Cross-cultural Risk Perception - A Survey Of Empirical Studies. The Netherlands, Kluwer Academic Publishers, 11-54.

30. Poortinga, W. and Pidgeon, N. F. (2003b). Exploring the dimensionality of trust in risk regulation. Risk Analysis, 23, 961-971.

31. Semadeni, M., Hansmann, R. and Flueler, T. (2004) Public attitudes in relation to risks and novelty of future energy options, Energy and Environment, 15, 755-777.

32. Hansla, A., Gamble, A., Juliusson, A. and Garling, T. (2008). Psychological determinants of attitude towards and willingness to pay for green electricity. Energy Policy, 36, 768-774.

33. MORI Scotland for BBC Scotland (2005). Hebridean Windfarm Plans. UK: MORI Social Research Institute.

34. London Renewables (2003). Attitudes To Renewable Energy In London: Public And Stakeholder Opinion And The Scope For Progress. London; Greater London Authority.

35. McGowan, F. and Sauter, R. (2005). Public Opinion On Energy Research: A Desk Study For The Research Councils. Brighton, Sussex: Science and Technology Policy Research (SPRU).

36. RSPB (2001). RSPB Market Research Project 0136: The GB Public's View On Energy Issues. London, BMRB.

37. Shackley, S. and McLachlan, C. (2006). Trade-offs in assessing different energy futures: a regional multi-criteria assessment of the role of carbon dioxide capture and storage. Environmental Science \& Policy, 9, 376-391.

38. Kaatsch, P., Spix, C., Schultz-Rath, R., Schmiedel, S. and Blettner, M. (2008) Leukaemia an young children living in the vicinity of German nuclear power plants. International Journal of Cancer, 1220, 721-726.

39. Schrader-Frechette K (2005). Mortgaging the future: Dumping ethics with nuclear waste. Science and Engineering Ethics. 2005, 11(4), 518-520.

40. Eiser, J. R., Van Der Pligt, J., and Spears, R. (1995). Nuclear Neighbourhoods: Community Responses to Reactor Siting. Exeter, Devon: University of Exeter Press.

41. Slovic, P. (2000). The Perception Of Risk. London: Earthscan.

42. NIA/MORI (2007). Public Attitudes To The Nuclear Industry. London, UK: MORI Social Research Institute.

43. Ansolabahere, S. (2007). Public Attitudes Towards America's Energy Options: Report Of The 2007 MIT Energy Survey. Massachusetts, US: CEEPR (Center for Energy and Environmental Policy Research).

44. Eurobarometer (2008). Attitudes Towards Radioactive Waste (Special Eurobarometer 297). Europe: European Commission. 
45. Castro, P. (2006). Applying social psychology to the study of environmental concern and environmental worldviews: Contributions from the social representations approach. Journal of Community and Applied Social Psychology, 16, 247-266.

46. Darley, J. M. and Gilberrt, D. T. (1985). Social psychological aspects of environmental psychology. In G. Lindzey and E. Aronson (Eds.), The Handbook Of Social Psychology, $3^{\text {rd }}$ edition, Volume II (pp. 949-991). Reading, MA: Addison Wesley.

47. Dunlap, R. E. and Catton, W. R. (1979). Environmental sociology. Annual Review of Sociology, 5, 243-273.

48. Dunlap, R. E. and Van Liere, K. D. (1978). The new environmental paradigm. Journal of Environmental Education, 9, 10-19.

49. Douglas, M. and Wildavsky, A. (1982). Risk And Culture: An Essay On The Selection Of Technical And Environmental Dangers. Berkeley: University of California Press.

50. Dake, K. and Wildavsky, A. (1991). Individual differences in risk perception and risktaking preferences. In B. J. Garrick and W. C. Gekler (Eds.), The Analysis, Communication And Perception Of Risk (pp. 98-117). New York: Plenum.

51. Schwarz, M. and Thompsn, M. (1990). Divided We Stand. Redefining Politics, Technology And Social Choice. Exeter, UK: Wheatons.

52. Ellis, R. J. and Thompson, F. (1997). Culture and the environment in the Pacific Northwest. American Political Science Review, 91, 885-897.

53. Peters, E. and Slovic, P. (1996). The role of affect and worldviews as orienting dispositions in the perception and acceptance of nuclear power. Journal of Applied Social Psychology, 26, 1427-1453.

54. Jenkins-Smith, H. C. (1993). Nuclear Imagery And Regional Stigma: Testing Hypotheses Of Image Acquisition And Valuation Regarding Nevada. Albuquerque, NM: University of New Mexico, Institute for Public Policy.

55. Webber, D. J. (1982). Is nuclear power just another environmental issue? Environment and Behaviour, 14, 72-83.

56. Levi, D.J. and Holder, E.E. (1986). Nuclear power: The dynamics of acceptability. Environment and Behaviour, 18, 385-395.

57. Borcherding, K., Rohrmann, B. and Eppel, T. (1986). A psychological study on the cognitive structure of risk evaluations. In Brehmer, B., Jungermann, H., Lourens, P. and Sevon, G. (Eds.) New Directions In Research On Decision Making, (pp 245-262). Amsterdam: Elsevier.

58. Sjöberg, L. (2003). Distal factors in risk perception. Journal of Risk Research, 6, 187211.

59. Gough, C. and Shackley, S. (2002). The respectable politics of climate change: The epistemic communities and NGOs. International Affairs, 77, 329-346.

60. Menard, S. (1995). Applied Logistic Regression Analysis. Sage University Paper Series On Quantitative Applications In The Social Sciences, 07-106. Thousand Oaks, CA: Sage. 
61. MacKinnon, D. P., Krull, J. L. and Lockwood, C. M. (2000). Equivalence of the mediation, confounding and suppression effect. Prevention Science, 1, 173-181.

62. Buss, D.M., Craik, K.H. and Dake, K. (1986) Contemporary worldviews and the perception of the technological system. In V.T Covello, J. Menkes and J. Mumpower (Eds) Risk Evaluation And Management. New York: Plenum.

63. Whitfield, S. C., Rosa, E. A., Dan, A. and Dietz, T. (2009). The future of nuclear power: Value orientations and risk perception. Risk Analysis, 29, 425-437.

64. DEFRA (2007). Climate Change Bill. London: HM Government.

65. Venables, D., Pidgeon, N.F., Simmons, P., Henwood, K. and Parkhill, K. (2009) Living with nuclear power in Britain: A Q-method study of local community perceptions. Risk Analysis, 29, 1089-1104

66. Finucane, M. L., Alhakami, A., Slovic, P. and Johnson, S. M. (2000). The affect heuristic in judgements of risks and benefits. Journal of Behavioural Decision Making, 13, 1-7.

67. Siegrist, M., Keller, C. and Cousin, M. (2006). Implicit attitudes toward nuclear power and mobile phone base stations: Support for the Affect Heuristic. Risk Analysis, 1021-1029.

68. Rosa, E.A. and Clark, D. L. (1999). Historical routes to technological gridlock: Nuclear technology as prototypical vehicle. Research in Social Problems and Public Policy, 7: 21-57.

69. UKERC (2009). Making The Transition To A Secure And Low-Carbon Energy System: Synthesis Report. London: UKERC. 
